\title{
E-Ensiklopedia Pengobatan Islam Berbasis Web
}

\author{
Ella Mutiara Leavy ${ }^{1 *}$, Endang Supriyati ${ }^{1}$, dan Tri Listyorini ${ }^{3}$ \\ $1,2,3$ Universitas Muria Kudus \\ Gondangmanis Bae, Kudus 59532 \\ Corresponding author's e-mail: ella.m.leavy@gmail.com
}

\begin{abstract}
Abstrak - Informasi mengenai pengobatan dengan metode Islam telah banyak dijumpai sebagai kumpulan data buku, artikel, maupun literatur lain. Pencarian informasi secara manual dinilai kurang efisien karena membutuhkan lebih banyak waktu. Informasi pengobatan Islam perlu dirangkum, dikumpulkan, dan diolah dalam sebuah sistem informasi yang dapat diakses secara lebih cepat dibandingkan dengan pencarian manual sehingga lebih memudahkan pengguna untuk memperoleh informasi yang diinginkan. Data diperoleh dari berbagai sumber termasuk Alquran dan Hadits, yang kemudian dirancang menggunakan ontologi dan tool protege secara konvensional. Data yang telah dirancang kemudian diterapkan dalam sebuah sistem informasi berbasis web. Sistem informasi mengenai pengobatan Islam ini dapat digunakan oleh pengguna untuk mendapatkan informasi mengenai penyakit dan pengobatan yang dianjurkan menurut ajaran Islam.

Kata kunci: Web, Protege, Pengobatan Islam
\end{abstract}

Abstract - Information about treatment with Islamic method has been found as a collection of data as book, articles and other literature. Manually searching for that information is considered less efficient because it requires more time. Information on Islamic medicine needs to be summarized, collected and processed in an information system that can be accessed more quickly than manual searches, making it easier for users to obtain the desired information. Data were obtained from various sources including the Koran and Hadith, which designed using a conventional ontology and tool protege. The data that has been designed then applied in a web-based information system. This information system regarding Islamic medicine can be used by users to get information about diseases and the treatments recommended according to Islamic way.

Keywords : Web, Protege, ontology, Islamic Medicine

\section{Pendahuluan}

Pengobatan adalah suatu upaya yang dilakukan untuk mengembalikan kesehatan tubuh setelah terjangkit suatu penyakit. Metode pengobatan yang paling umum dilakukan sekarang ini adalah pengobatan dengan metode medis oleh para dokter dan tenaga kesehatan. Meskipun begitu, masih banyak masyarakat khususnya masyarakat Indonesia yang lebih menyukai pengobatan dengan metode selain dari metode medis. Metode alternatif menjadi metode yang banyak dilakukan didasarkan pada kajian-kajian agama, dalam hal ini mengacu pada pengobatan secara Islami yang dianjurkan oleh Rasulullah SAW pada masa kenabian. Maksud dari pengobatan yang dianjurkan Rasulullah SAW tersebut adalah pengobatan yang digunakan untuk mengobati penyakit hati (penyakit rohani) maupun penyakit jasmani (penyakit badan) tanpa mengacu pada ramuan obatobatan dalam istilah farmasi dan medis yang selama ini kita ketahui. Metodenya bukan hanya spesifik dalam mengobati suatu penyakit yang telah menjangkit, namun juga tindakan pencegahan dan menjaga tubuh agar tetap sehat.

Semakin banyak literatur yang memuat pengobatan Islami, semakin sering digunakan sebagai acuan masyarakat. Untuk melakukan metode yang tepat harus mencari informasi dari literatur yang ada, sehingga tidak efisien waktu. dalam perkembangan literatur pengobatan dan tata caranya, telah banyak yang merangkumnya dalam sebuah sistem informasi, namun pengobatan secara Islam belum dirangkum dengan cukup baik. adanya web sistem informasi mengenai pengobatan Islam dapat diharapkan memudahkan pencarian informasi dan mengatasi masalah efisiensi waktu. Pengguna dapat mengakses sistem dan mencari informasi yang diinginkan secara lebih cepat dan mudah tanpa harus mencari dari kumpulan data pada buku pengobatan dan artikel yang tersebar.

Data yang telah dikumpulkan akan diolah menggunakan ontologi melalui piranti protege. Dalam penelitian ini, ontologi tidak diterapkan langsung dalam web. Ontologi dalam hal ini digunakan untuk memodelkan hubungan antar objek data yang telah dikumpulkan sebelumnya.

\section{Tinjauan Pustaka}

2.1. Pengobatan Islam

Upaya penyembuhan penyakit menurut Nabi Muhammad SAW, pengobatan tidak bergantung pada pengobatan yang dapat menimbulkan syirik atau menyekutukan Allah, namun cenderung lebih meyakini 
hubungan diri dengan Allah merupakan penyembuh penyakit[1]. Perkembangan dunia farmasi Islam lebih dulu unggul dibandingkan dengan perkembangan farmasi di zaman gelap yang melanda kaum barat hingga abad 12[2]. Nabi Muhammad SAW menganjurkan penanganan suatu penyakit melalui tiga tahapan. Yang pertama adalah pengobatan menggunakan obat-obatan alamiah, yang kedua dengan obat-obatan ilahiah, yang ketiga merupakan gabungan di antara keduanya.[3]

2.2. Sistem Informasi

Sistem informasi merupakan sistem yang menyediakan informasi sebagai kombinasi teknologi dan informasi, serta aktivitas pengguna teknologi tersebut untuk mendukung manajemen dan operasi. Sistem informasi sering diartikan sebagai interaksi antar orang, proses, algoritmik dan data serta teknologi.[4]

2.3. Website

Website adalah kumpulan halaman yang dapat menampilkan informasi data berupa teks, gambar, animasi, video, suara dan gabungan dari semua data tersebut. Informasi tersebut saling terhubung dengan jaringan halaman, baik yang sifatnya statis maupun dinamis.[5]

2.4. PHP

PHP adalah salah satu bahasa yang dipakai dalam pembuatan sebuah website untuk menerjemahkan baris kode sumber menjadi kode mesin. PHP digunakan dalam bentuk script yang diletakkan dalam server web. Bahasa pemrograman PHP berjalan pada sisi server.[6]

2.5. MySQL

MySQL adalah perangkat lunak atau software manajemen basis data yang bersifat open source. MySQL populer digunakan dengan SQL sebagai bahasa dasar untuk pengaksesan database.[7][8]

2.6. Ontologi

Ontologi dapat digunakan untuk memodelkan dan menghubungkan antar entitas objek. Ontologi adalah teori tentang makna, properti dan relasi objek yang terjadi pada suatu domain pengetahuan. Ontologi merupakan dokumen atau file yang mendefinisikan hubungan antar teks. Dalam penyusunan ontologi terdapat penentuan scope, terms, class dan hierarchy class. [9]

2.7. Protege

Protege adalah perangkat lunak untuk pengembangan pengetahuan berbasis sistem dan bahan pengujian menggunakan sample data yang ada. [10][11]

\section{Metode Penelitian}

Dalam penelitian ini terdapat kerangka langkah-langkah guna mendapat penyelesaian dari permasalahan yang diteliti.

1. Pengumpulan data

Pengumpulan data dimulai dari tahap kajian awal, lalu pengumpulan data sekunder yang bersumber dari beberapa literatur.

2. Analisa kebutuhan

Analisa kebutuhan dibagi menjadi dua, yaitu analisa kebutuhan fungsional dan analisa kebutuhan nonfungsional.

3. Konstruksi ontologi

Konstruksi ontologi dalam penelitian ini adalah merancang domain pengobatan Islam melalui tahapan ontologi.

4. Perancangan sistem

Perancangan sistem dimulai dari perancangan basis data dan pembuatan UML.

5. Pembuatan sistem

Pembuatan sistem dikerjakan menggunakan bahasa pemrograman PHP.

6. Pengujian sistem

Sistem yang telah selesai dibuat kemudian diuji menggunakan metode pengujian black box.

7. Implementasi sistem

Pada tahap ini sistem telah dapat dioperasikan.

\section{Hasil dan Pembahasan}

Ontologi disusun berdasarkan tahapan-tahapan ontologi. Scope yang digunakan dalam penelitian ini adalah pengobatan Islam. Terms diambil dari istilah-istilah yang berkaitan dengan pengobatan Islam. Hasil dari perancangan ontologi tersebut adalah gambaran umum ontologi pengobatan Islam dan properties yang menyertai gambaran umum, yang dapat dilihat pada gambar 1 . 


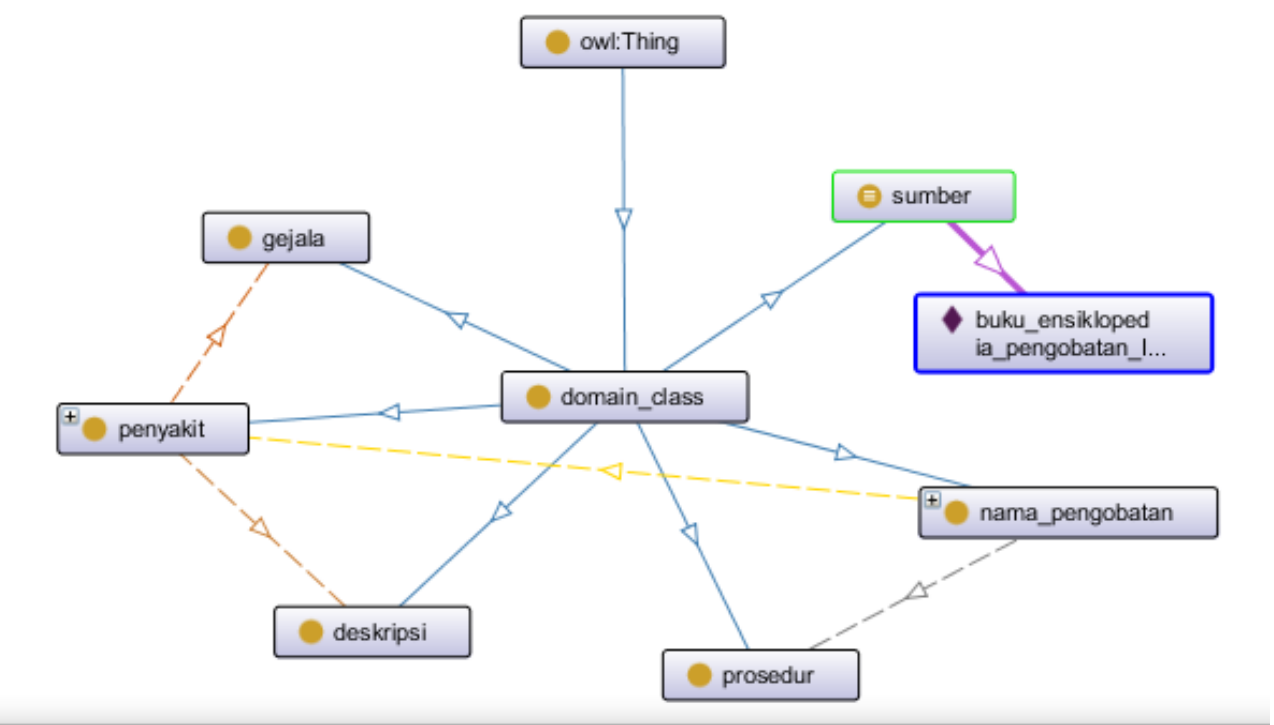

Gambar 1. Ontograf menurut properties

UML juga diperlukan dalam pembuatan sistem, salah satunya adalah Use Case Diagram. Use Case Diagram merupakan jenis diagram UML yang memiliki interaksi yang berurutan serta saling terkait antar user dan sistem. Gambar 2 menunjukkan Use Case Diagram pada penelitian.

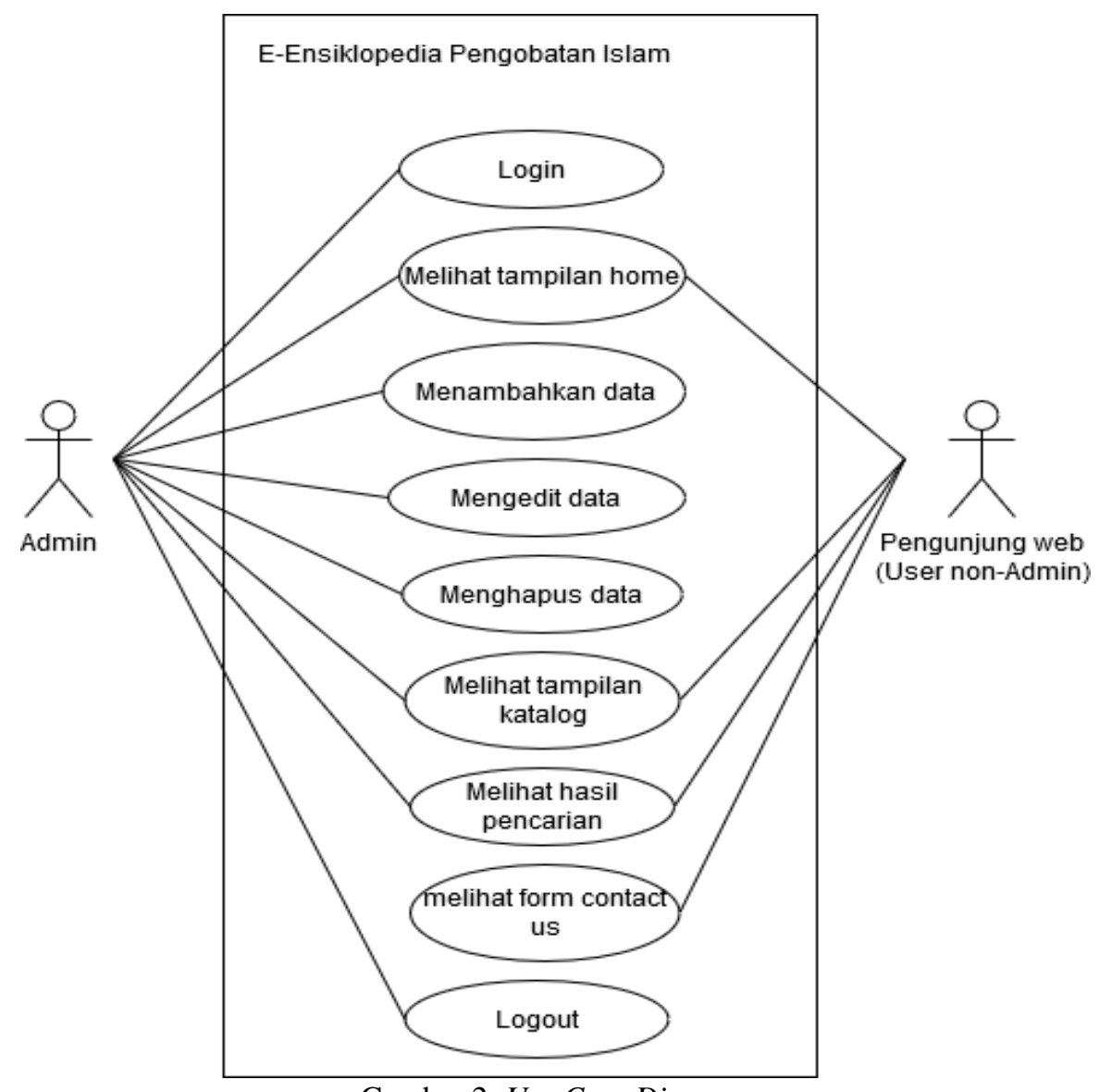

Gambar 2. Use Case Diagram

Implementasi sistem menurut pengunjung web secara garis besar dapat dilihat pada gambar 3, gambar 4 
dan gambar 5, sedangkan implementasi sistem menurut admin dapat dilihat pada gambar 6 .

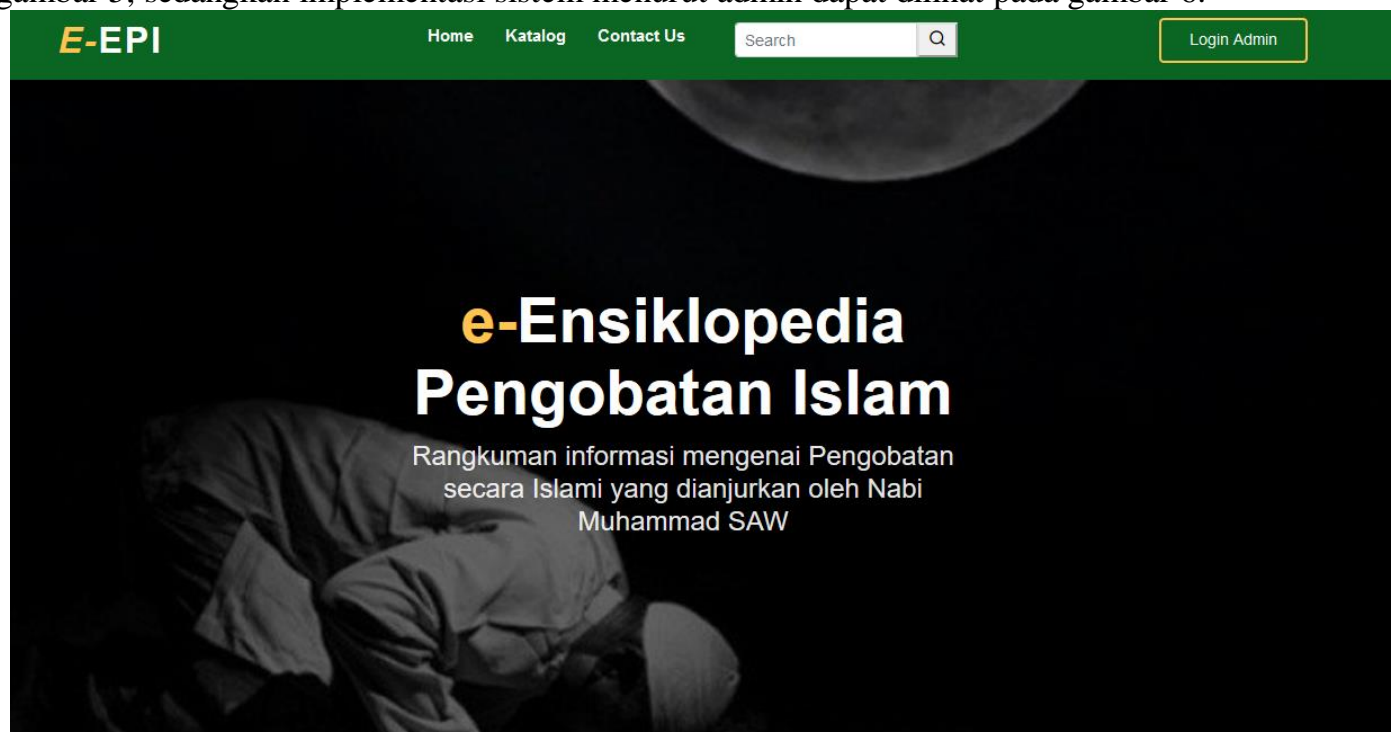

Gambar 3. Tampilan menu home

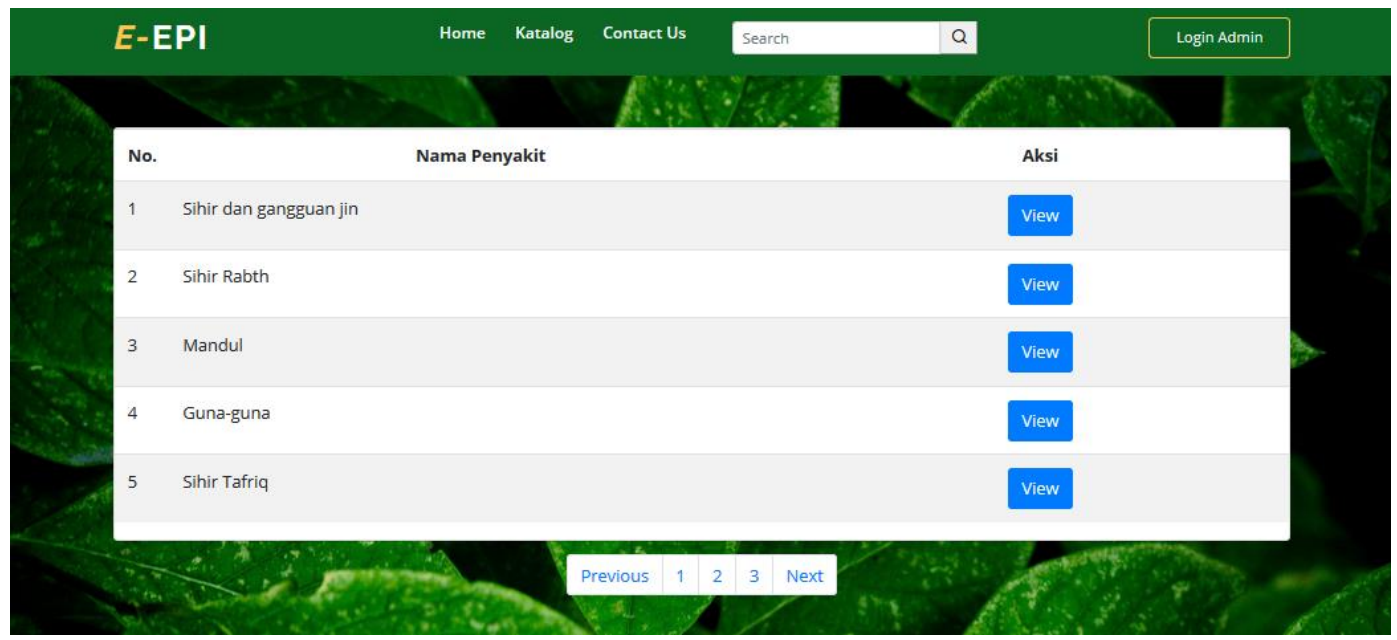

Gambar 4. Tampilan menu katalog 


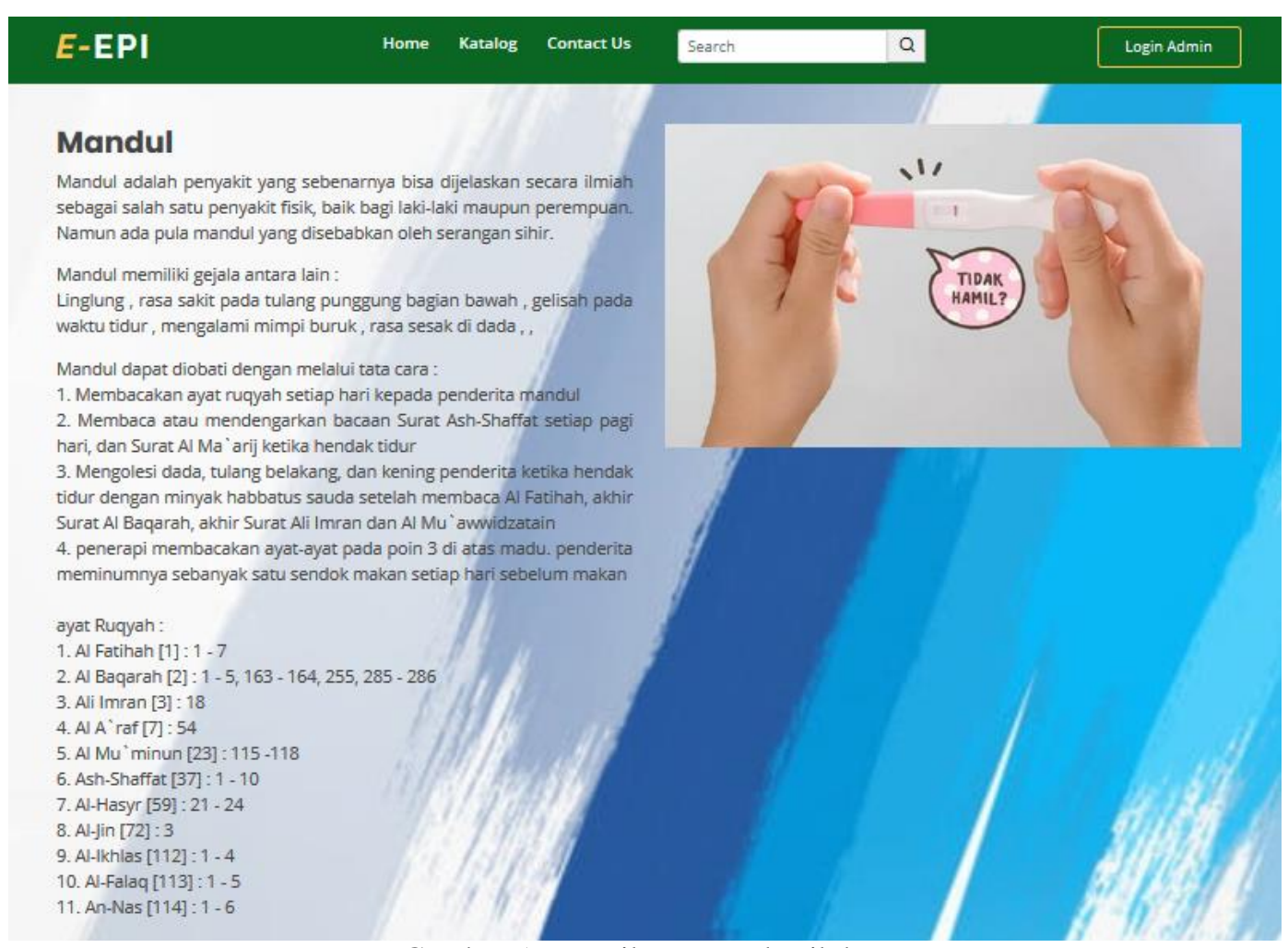

Gambar 5. Tampilan menu detail data

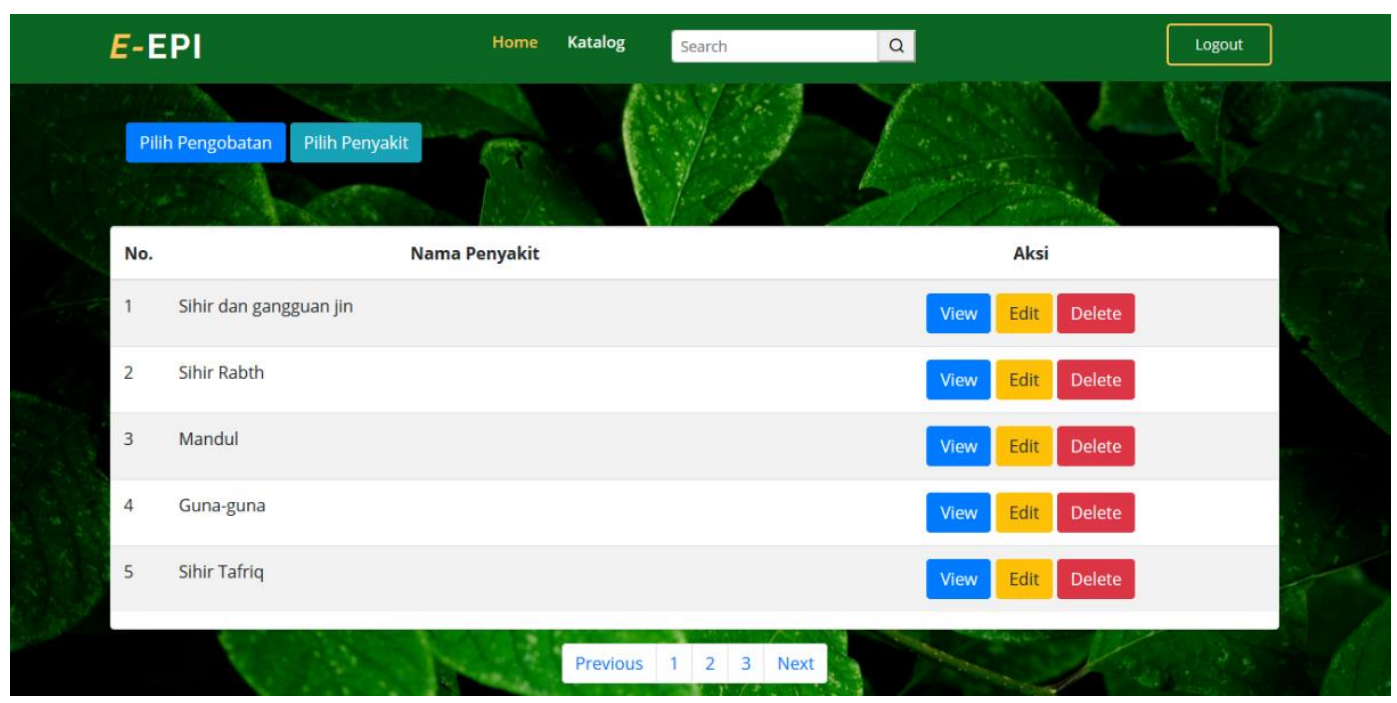

Gambar 6. Menu katalog admin

\section{Kesimpulan}

Kesimpulan dari penelitian :

1. Dengan adanya sistem informasi berbasis web, pencarian informasi pengobatan dengan cara Islami dapat dilakukan lebih cepat dibandingkan dengan mencari secara manual di buku.

2. Pengelolaan data sepenuhnya menjadi tanggung jawab admin, sehingga tidak sembarang orang dapat memalsukan data.

3. Pengunjung web dapat mengirim masukan kepada admin mengenai kesalahan data melalui alamat email admin yang dicantumkan dalam menu Contact Us.

4. Sistem informasi ini dapat dikembangkan agar dapat menjangkau lebih banyak orang di berbagai belahan dunia. 


\section{Daftar Pustaka}

[1] M. Ihsan, "Pengobatan ala Rasulullah SAW sebagai Pendekatan Antropologis dalam Dakwah Islamiah di Desa Rensing Kecamatan Sakra Barat," Palapa, vol. 4, no. 2, pp. 152-210, 2016.

[2] S. Sudewi and S. M. Nugraha, "Sejarah Farmasi Islam dan Hasil Karya Tokoh-Tokohnya," Aqlam J. Islam Plur., vol. 2, no. 1, pp. 57-72, 2018.

[3] S. A. Salim, "Ensiklopedi Pengobatan Islam." Pustaka Arafah, Solo, 2018.

[4] Suhartini, M. Sadali, and Y. K. Putra, "Sistem Informasi Berbasis Web Sma Al- Mukhtariyah Mamben Lauk Berbasis Php Dan Mysql Dengan Framework Codeigniter," vol. 3, no. 1, pp. 79-84, 2020.

[5] A. Suprianto and A. A. F. Matsea, "Rancang Bangun Aplikasi Pendaftaran Pasien Online Dan Pemeriksaan Dokter Di Klinik Pengobatan Berbasis Web," J. Rekayasa Inf., vol. 7, no. 1, pp. 48-58, 2018.

[6] P. Ayu, W. Purnama, and T. A. Putra, "Perancangan Sistem Penjualan Berbasis Web ( E-Commerce ) Pada Toko DMX Factory Outlet Dengan Menggunakan Bahasa Pemrograman PHP-MYSQL Dan Java Script," Manaj. Inform. Komput., vol. 5, no. 1, pp. 129-133, 2020.

[7] D. D. Hutagalung and F. Arif, "Rancang Bangun Sistem Informasi Perpustakaan Berbasis Web Pada Smk Citra Negara Depok," J. Chem. Inf. Model., vol. 53, no. 9, pp. 1689-1699, 2018.

[8] M. Munawir, S. Susmanto, Z. Zulfan, and Y. Yanti, "Sistem Pelayanan Surat Administrasi Masyarakat Gampong Berbasis Webbase dengan menggunakan Framework CodeIgniter," J. Serambi Eng., vol. 5, no. $1,2020$.

[9] F. Haris and S. Jayanti, "Rancang Bangun Ensiklopedia Tanaman Obat Kalimantan Tengah Berbasis Android," Sebatik, vol. 23, no. 1, pp. 218-223, 2019.

[10] H. Jusuf et al., "Perancangan Web Semantik Aplikasi Pencarian Tumbuhan Obat," pp. 28-29, 2016.

[11] A. A. Mamusung, N. B. Anshary, and R. A. Sumarni, "Perancangan Sistem Monitoring Gangguan Akses Wifi. Id PT Telkom Wilayah Jakarta Timur Berbasis Netbeans," J. Nas. Komputasi dan Teknol. Inf., vol. 3 , no. 3, pp. 255-261, 2020. 